Hydrol. Earth Syst. Sci., 15, 3679-3688, 2011

www.hydrol-earth-syst-sci.net/15/3679/2011/

doi:10.5194/hess-15-3679-2011

(c) Author(s) 2011. CC Attribution 3.0 License.

\title{
Spatial variation of the longitudinal dispersion coefficient in an estuary
}

\author{
D. C. Shaha ${ }^{1}$, Y.-K. Cho ${ }^{1}$, M.-T. Kwak ${ }^{1}$, S. R. Kundu ${ }^{2}$, and K. T. Jung ${ }^{3}$ \\ ${ }^{1}$ School of Earth and Environmental Sciences, Research Institute of Oceanography, Seoul National University, \\ Seoul 151-742, Korea \\ ${ }^{2}$ Department of Oceanography, Chonnam National University, Gwangju 500-757, Korea \\ ${ }^{3}$ Korea Ocean Research and Development Institute, Ansan 425-600, Korea
}

Received: 7 June 2011 - Published in Hydrol. Earth Syst. Sci. Discuss.: 12 August 2011

Revised: 1 November 2011 - Accepted: 14 November 2011 - Published: 7 December 2011

\begin{abstract}
The effective longitudinal dispersion is a primary tool for determining property distributions in estuaries. Most previous studies have examined the longitudinal dispersion coefficient for the average tidal condition. However, information on spatial and temporal variations of this coefficient at low and high tides is scarce. Three years of hydrographic data taken at low and high tide along the main axis of the Sumjin River Estuary (SRE), Korea are used to estimate the spatial and temporal variation of the effective longitudinal dispersion coefficient. The range of the dispersion coefficient is rather broad at high water slack (HWS) and narrower at low water slack (LWS) because of the different tidal amplitudes. The spatially varying dispersion coefficient has maximal values $\left(>300 \mathrm{~m}^{2} \mathrm{~s}^{-1}\right)$ near the mouth at high water and decreases gradually upstream, with fluctuations. The temporally varying dispersion coefficient appears to be positively correlated with river discharges at both low and high tide. The dispersion varies with the square root of river discharges at HWS and LWS. The dispersive salt fluxes increases with increasing river discharges and decreases with decreasing river discharges at HWS and LWS. Estimation of the numerical values of the effective longitudinal dispersion coefficient in the SRE can be useful for better understanding of the distributions of other tracers in the SRE as well as for developing and testing hypotheses about various mixing mechanisms.
\end{abstract}

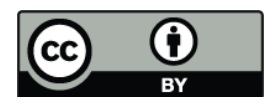

Correspondence to: Y.-K. Cho

(choyk@snu.ac.kr)

\section{Introduction}

Pollutants enter rivers by many routes, including runoff from agricultural land, industrial and municipal wastewater, and tributary discharge. Physical processes such as advective transport and dispersion play key roles in determining the movement and changes in concentration of these contaminants after they enter a river. Thus, advection and dispersion are fundamental variables for the evaluation of water quality in aquatic systems by conceptual or numerical models (Garcia-Barcina et al., 2006; Ji, 2008). The dispersion coefficient can be estimated using tracer experiments (Caplow et al., 2003; Ho et al., 2002), but these experiments are logistically complex and time consuming. However, the spatial and temporal distribution of salinity in an estuary sampled non-synoptically is a useful indicator of the system's physical condition because it represents the net effect of numerous complex processes such as the freshwater inflow, tidal range, and degree of turbulence (Lewis and Uncles, 2003; Eaton, 2007).

Dispersive processes in an estuary are usually estimated by a dispersion coefficient $D_{i}(x)$ using salinity as a tracer. $D_{i}(x)$ is usually defined as the ratio of the non-advective transport rate of salt (or other substances) through a unit cross-sectional area to the salinity gradient along the main axis of the estuary (Dyer, 1997; Savenije, 2005). The tidally averaged approach has been used by many authors to understand the temporal variation of the longitudinal dispersion coefficient (Paulson, 1970; Officer, 1976; Dyer, 1997; Lewis and Uncles, 2003). However, the spatial variation of $D_{i}(x)$ in estuaries at low and high tides has received

Published by Copernicus Publications on behalf of the European Geosciences Union. 
little attention. The tidally averaged salt balance equation has been integrated for high water slack (HWS) and low water slack (LWS) conditions (Savenije, 1989, 2005), which are of greater interest in this study for determining the effective longitudinal dispersion coefficient based on observed axial depth-averaged salinity distributions of an estuary. Eaton (2007) noted that the spatial distributions of the dispersion coefficient depend strongly on ground-water discharge and are most sensitive at LWS.

The numerical values of this longitudinal dispersion coefficient in estuaries are comparatively difficult to determine and interpret because the motion of solutes in estuaries is influenced by river discharge, tidal variations, bed friction, channel topography and density gradients (Guymer and West, 1992; Geyer and Signell, 1992; Vallino and Hopkinson, 1998; Austin, 2004). The effective longitudinal dispersion varies temporally and increases with freshwater inflow (Paulson, 1970; Garvine et al., 1992; Dyer, 1997; Austin, 2004). In contrast, the $D_{i}(x)$ values decline with an increase in tidal range (Lewis and Uncles, 2003). This is because the dispersive action becomes less effective under more turbulent conditions as turbulence generated by strong tidal amplitude effectively reduces the dispersing action of velocity shears (Linden and Simpson, 1988). Moreover, Linden and Simpson (1988) reported that $D_{i}(x)$ increases with the horizontal density gradient and also with the period of the turbulence modulation. The dispersive flux of salt is particularly sensitive near the maximum salinity gradient (Lewis and Uncles, 2003).

The Sumjin River discharges into Gwangyang Bay on the south coast of Korea. No information is available about the typical magnitude of $D_{i}(x)$ along the Sumjin River Estuary (SRE) or how it changes with variations in freshwater discharge, tidal height, and salinity gradient along the SRE. The purpose of this study is to determine the effective longitudinal dispersion coefficient at low and high tides in the SRE, which are ultimately responsible for transporting salt upstream. In addition, the effects of freshwater discharge, tidal height and salinity gradient on the spatially varying longitudinal dispersion coefficient are examined. A better knowledge of the numerical magnitude of the effective longitudinal dispersion, with some indications of the spatial and temporal variability of this dispersion coefficient, may be useful for developing three dimensional numerical models with more realistic physical fields, which would be helpful for understanding of biological and chemical distributions in the SRE.

The rest of this paper is organized as follows. The study area and data sources are briefly presented in Sect. 2. The methods are described in Sect. 3. The results and discussion are presented in Sect. 4 . The conclusions are summarized in Sect. 5.

\section{Study site and data}

The Sumjin River splits into east and west channels near the Pohang Iron and Steel Company (POSCO) before it enters Gwangyang Bay. The bay is connected in the south to the coastal ocean (South Sea) and in the east to Jinjoo Bay through the narrow Noryang Channel (Fig. 1). The cross-sectional area $\left(\mathrm{m}^{2}\right)$, width $(\mathrm{m})$, and depth $(\mathrm{m})$ of crosssections of all CTD stations of the SRE were calculated by using Surface Water Modeling System grid generation software (version 8.1) (Shaha and Cho, 2011). The watershed area of the SRE, including farmland, is almost $4900 \mathrm{~km}^{2}$. Seasonal precipitation and runoff in the Sumjin River basin decrease in spring and winter, and increase in summer (Bae et al., 2008). The daily mean rive discharge has been obtained from Songjung gauge station located about $11 \mathrm{~km}$ upstream from CTD station 24 . The maximum monthly median river discharge was highest $\left(370 \mathrm{~m}^{3} \mathrm{~s}^{-1}\right)$ in July 2006 and lowest $\left(11 \mathrm{~m}^{3} \mathrm{~s}^{-1}\right)$ in January 2005. Tidal information has been collected over the observation period from the Gwangyang Tidal Station (GT1, Fig. 1), operated by the Korea Hydrographic and Oceanographic Administration. The tidal cycle is semi-diurnal, with mean spring and neap ranges of 3.40 and $1.10 \mathrm{~m}$, respectively.

We recently acquired three years of conductivitytemperature-depth (CTD) profiles using Ocean Seven 304 CTD sensors (IDRONAUT Company) at 25 stations distributed along the SRE to cover most of the range over which salt intrudes from Gwangyang Bay. The nominal distance between CTD stations was $1 \mathrm{~km}$. A total of 24 longitudinal salinity transects were obtained at low and high tide during spring tide in each season from August 2004 to April 2007. A Global Positioning System was used to obtain the location of the CTD stations. On the basis of the stratification parameter, which is the ratio of the salinity difference between the surface and the bottom divided by the depth-averaged salinity, the SRE shows partially or well-mixed condition during spring tide (Shaha and Cho, 2009).

\section{Methods}

By assuming equilibrium between advective and dispersive fluxes under tidal average conditions, Savenije (1986, 1989, 2005) integrated the salt balance equation with respect to $x$ to give

$$
Q\left(S_{\mathrm{TA}}-S_{\mathrm{f}}\right)-A_{\mathrm{TA}} D_{\mathrm{TA}} \frac{\partial S_{\mathrm{TA}}}{\partial x}=0
$$

where $Q$ is the freshwater discharge, $S_{\mathrm{TA}}$ represents the mean tidal steady-state salinity, $S_{\mathrm{f}}$ is the freshwater salinity, $A_{\mathrm{TA}}$ is the tidal average cross-sectional area and $D_{\mathrm{TA}}$ is the longitudinal dispersion coefficient. This equation can also be used to determine the longitudinal dispersion coefficient under HWS and LWS conditions (Savenije, 1989, 2005). Assuming the salinity $S_{\mathrm{f}}$ of freshwater discharge is zero, this equation can 


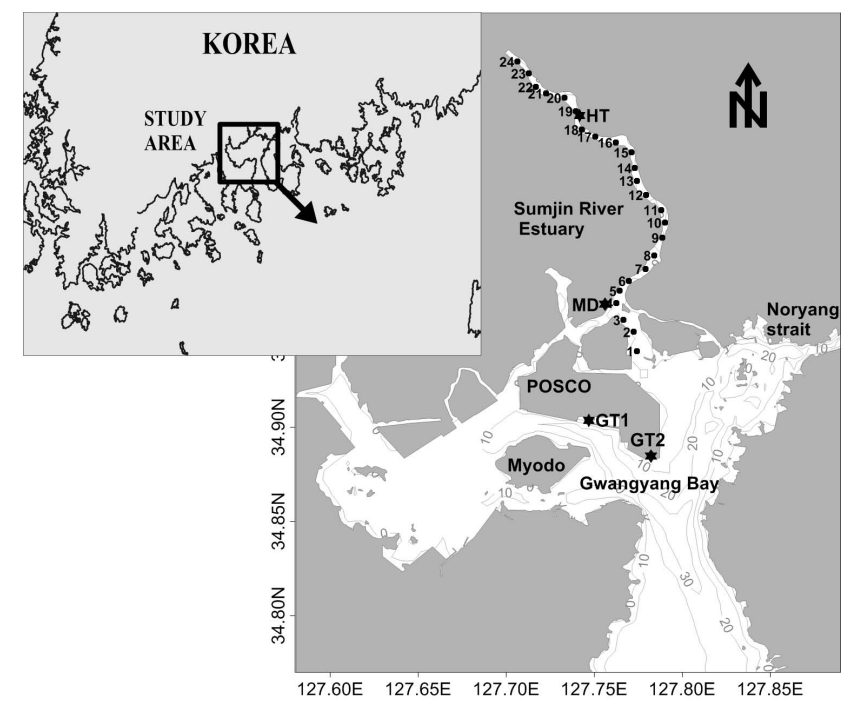

Fig. 1. Map of the study area. Solid circles indicate CTD stations. Stars denote the Gwangyang (GT1 and GT2), Mangdock (MD) and Hadong (HT) tide observation stations.

be expressed in general form for the spatially varying dispersion coefficient $D_{i}(x)$ as follows:

$D_{i}(x)=\frac{Q S_{i}(x) / A_{i}(x)}{\frac{\partial S_{i}}{\partial x}}$

where the subscript $i$ corresponds to HWS or LWS conditions. The longitudinal dispersion coefficient $D_{i}(x)$ is a bulk parameter that is used in simple models to characterize the overall diluting capacity of an estuary (Dyer, 1997; Lewis and Uncles, 2003; Savenije, 1989, 2005). Simple models are valuable for estuarine water-quality studies but there is necessity to understand better what $D_{i}(x)$ represents physically (Lewis and Uncles, 2003). A little is known about the typical magnitude of $D_{i}(x)$ in estuaries at LWS and HWS conditions, or how it varies over space and time in response to changes in channel morphology, freshwater discharge and tidal amplitude (Fischer et al., 1979; Lewis and Uncles, 2003; Gay and O'Donnell, 2009).

Therefore, it is important to obtain a better quantitative knowledge of the dispersive characteristics of an estuary. $\mathrm{D}_{i}(x)$ can be calculated at LWS and HWS along the SRE; because $Q, A_{i}(x)$ and the salinity distribution $S_{i}(x)$ along the axis of the SRE for three years are available. The numerator represents the advective rate of transport of salt seawards by the river flow, $Q$ per unit area of cross-section $A(x)$. This is countered by the landward flux of salt due to nonadvective processes. The denominator represents the longitudinal salinity gradient. As the salinity gradient also has dependence on the strength of the vertical circulation, it is conceivable that the ratio given in Eq. (2) does not represent the effects of vertical salinity gradient on the dispersion due to using depth-averaged salinity. Therefore, Eq. (2) is inappli- cable to stratified conditions (Dyer, 1997). However, Eq. (2) describes the coefficient of effective longitudinal dispersion for well-mixed estuaries (Dyer, 1997; Savenije, 1989, 2005). Therefore, this simple advection-dispersion model of the salt distribution is applied to the SRE under partially to wellmixed conditions during spring tide.

The effects of longitudinal salinity gradient and the magnitude of $D_{i}(x)$ on the salt flux in the SRE are taken into account to obtain insight. The non-advective transport, expressed as the rate of transport of salt per unit area, represents the salt flux $F_{\mathrm{S}}$ at the estuary location corresponding to the salinity gradient (Dyer, 1997).

$F_{\mathrm{s}}(x)=D_{i}(x) \frac{\partial S_{i}}{\partial x}$

$F_{\mathrm{s}}$ is expressed in units of $\mathrm{m} \mathrm{s}^{-1}$.

\section{Results and discussion}

\subsection{Longitudinal distribution of salinity and its gradient}

The depth mean salinity $\overline{S_{i}}$ with standard deviation at LWS and HWS is shown in Fig. 2 for all stations. The shape of the salt intrusion curve varies according to the range of river discharges. The river discharges are categorized as $5-15 \mathrm{~m}^{3} \mathrm{~s}^{-1}$, $16-30 \mathrm{~m}^{3} \mathrm{~s}^{-1}$, and $45-60 \mathrm{~m}^{3} \mathrm{~s}^{-1}$. A concave shape salt intrusion curve is found for river discharge of $5-15 \mathrm{~m}^{3} \mathrm{~s}^{-1}$ with small salinity gradient near the mouth (Fig. 2a). For river discharge of $45-60 \mathrm{~m}^{3} \mathrm{~s}^{-1}, 50 \%$ of the total salt intrusion curve is concave toward the mouth and another $50 \%$ is convex upstream. The salt intrusion curve for river discharge of $16-30 \mathrm{~m}^{3} \mathrm{~s}^{-1}$ is a mixture of the two. These salt intrusion curves are consistent with the curves described by Savenije (2005). The salt intrusion curves are mostly concave at LWS (Fig. 2b). The mean horizontal salinity gradients at high (low) tide according to the first-order polynomial fit (not shown) are $1.25(1.40) \mathrm{km}^{-1}, 1.44(1.48) \mathrm{km}^{-1}$ and $1.46(1.42) \mathrm{km}^{-1}$ for river discharges of $5-15 \mathrm{~m}^{3} \mathrm{~s}^{-1}$, $16-30 \mathrm{~m}^{3} \mathrm{~s}^{-1}$, and $45-60 \mathrm{~m}^{3} \mathrm{~s}^{-1}$, respectively (Fig. 2a). The first-order polynomial (linear function) fits give $R^{2}$ value of $>0.92$ at HWS and LWS. This simple fit predicts the landward end of the salt intrusion.

Figure 2 also shows the lower-order mean standard deviation of salinity over the length scale of the tidal excursion of $6 \mathrm{~km}$ near the mouth (Shaha and Cho, 2011), in which mixing occurs mainly by tidal effects, resulting in less variation in the salinity distribution and consequently yielding a lower standard deviation. The salt intrusion length is longer than the tidal excursion length scale, which characterizes the SRE as a coastal plain estuary (MacCready and Geyer, 2010). In contrast, the standard deviation is of higher order in the central regimes between 6 and $20 \mathrm{~km}$, where mixing occurs because of both tide-driven and density-driven circulation (Shaha et al., 2010), causing different salinity distributions and thus a higher standard deviation. 


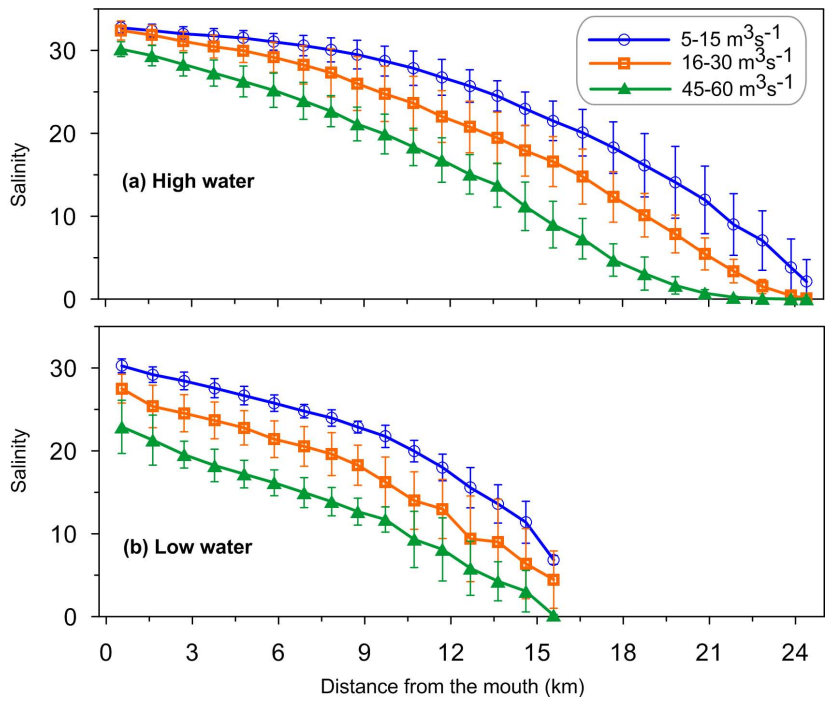

Fig. 2. Depth mean salinity distribution at high and low water slack in the Sumjin River Estuary under different river discharges.

The mean longitudinal salinity gradients along the SRE at low and high tides under different river discharges are shown in Fig. 3. At river discharge of $45-60 \mathrm{~m}^{3} \mathrm{~s}^{-1}$, the strength of the mean salinity gradient increases from downstream of the SRE to middle regimes and then decreases in the upper most regimes at LWS and HWS. However, a continuous landward increase of the salinity gradient is found at both HWS and LWS for river discharge of $5-15 \mathrm{~m}^{3} \mathrm{~s}^{-1}$ and $16-30 \mathrm{~m}^{3} \mathrm{~s}^{-1}$. The cross-sectional area of the SRE increases exponentially toward the mouth from upstream (Shaha and Cho, 2011). Therefore, the displacement of a given salinity is reduced at the seaward end of the SRE compared to upstream locations for mass balance; as a result the seaward advective transport of salt per unit area decreases near the mouth. Consequently, the salinity gradient increase landward from the SRE mouth at both LWS and HWS. An exception is found at high river discharge of $45-60 \mathrm{~m}^{3} \mathrm{~s}^{-1}$ at HWS where the salinity gradient falls after $17 \mathrm{~km}$ from the SRE mouth. Lewis and Uncles (2003) noted that estuarine locations with less-steep salinity gradients are relatively well-mixed, and those with steeper gradients are partially stratified. According to the longitudinal salinity gradient of the SRE, the well-mixed area can be approximated as extending up to $7 \mathrm{~km}$ from the estuary mouth with a salinity gradient of $<1$; and the partially mixed area can be approximated as extending between 7 and $20 \mathrm{~km}$ with a salinity gradient ranging from 1 to 2 at high water. These well - and partially mixed areas agree with those identified in the earlier studies of the stratification parameter (Shaha and Cho, 2009), estuarine parameter and potential energy anomaly (Shaha et al., 2010), and Van der Burgh's coefficient (Shaha and Cho, 2011).

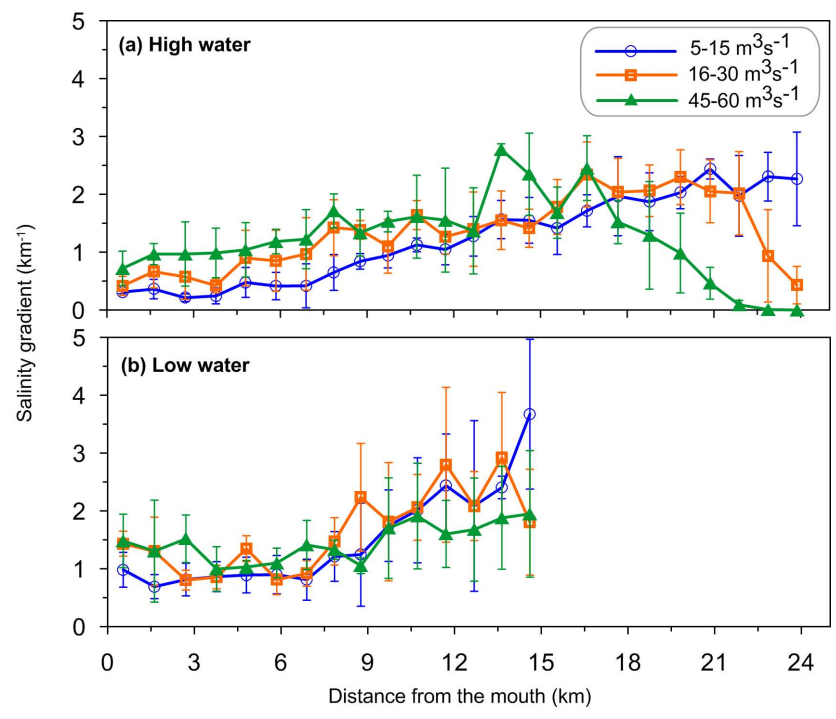

Fig. 3. Spatial variation in mean longitudinal salinity gradient along the Sumjin River Estuary at low and high tide under different river discharges.

\subsection{Longitudinal dispersion at low and high tides}

The relative abundance of salinity data in the SRE is used to estimate the distribution of the effective dispersion $D(x)$, which varies with time and location. The longitudinal dispersion increases with increasing river discharge (45$60 \mathrm{~m}^{3} \mathrm{~s}^{-1}$ ) and decreases with diminishing river discharges $\left(5-15 \mathrm{~m}^{3} \mathrm{~s}^{-1}\right)$. The range of dispersion coefficient values is rather broad for HWS (Fig. 4a). The values vary between 100 and $494 \mathrm{~m}^{2} \mathrm{~s}^{-1}$, with a mean value of $261 \mathrm{~m}^{2} \mathrm{~s}^{-1}$, at high tide for river discharge of $45-60 \mathrm{~m}^{3} \mathrm{~s}^{-1}$. The mean longitudinal dispersions are $171 \mathrm{~m}^{2} \mathrm{~s}^{-1}$ with a range of $44-470 \mathrm{~m}^{2} \mathrm{~s}^{-1}$ for river discharges of $5-15 \mathrm{~m}^{3} \mathrm{~s}^{-1}$, and $181 \mathrm{~m}^{2} \mathrm{~s}^{-1}$ with a range of 53-400 $\mathrm{m}^{2} \mathrm{~s}^{-1}$ for river discharges of $16-30 \mathrm{~m}^{3} \mathrm{~s}^{-1}$ at HWS. The spatially dependent structure has maximum mean values $\left(>300 \mathrm{~m}^{2} \mathrm{~s}^{-1}\right)$ due to the reduced salinity gradient near the mouth. This reduced gradient reflects a larger dispersion coefficient with higher standard deviation, and decreases gradually upstream after the tidal excursion length at HWS.

The dispersion coefficient in the SRE appears to increase from the mouth to $3 \mathrm{~km}$ and then rapidly decreases to the innermost SRE, the freshwater end, at both HWS and LWS conditions (Fig. 4), in agreement with results of Austin (2004). This also seems inconsistent with the expected increase of dispersion toward the mouth (Lewis and Uncles, 2003), which MacCready (1999) ascribes to the influence of the estuary cross-section on the largest possible eddies responsible for mixing. A summary of the estimated longitudinal dispersion coefficient values for the different estuaries of the world are given in Table 1. Prandle (1981) found a range of $D_{i}(x)$ values between 50 and $500 \mathrm{~m}^{2} \mathrm{~s}^{-1}$ 
Table 1. Summary of the estimated longitudinal dispersion coefficient for different estuaries.

\begin{tabular}{lll}
\hline Source & Estuary & $\begin{array}{l}\text { Longitudinal dispersion } \\
\text { coefficient }\left(\mathrm{m}^{2} \mathrm{~s}-1\right.\end{array}$ \\
\hline West and Williams (1972) & Ems estuary & $50-300$ \\
Prandle (1981) & A group of six estuaries & $50-500$ \\
Van de Kreeke (1990) & Volkerak estuary & $150-325$ \\
Vallino and Hopkinson (1998) & Parker River estuary & 670 (near mouth) \\
de Swart et al. (1997) & Ems estuary & $200-1200$ \\
Lewis and Uncles (2003) & Tees estuary & 100 \\
Lewis and Uncles (2003) & Severn estuary & 212 \\
Austin (2004) & Chesapeake Bay & $200-1000$, with a mean 650 \\
Banas et al. (2004) & Willapa bay & 710 (near the mouth) \\
& & 20 (upstream) \\
\hline
\end{tabular}

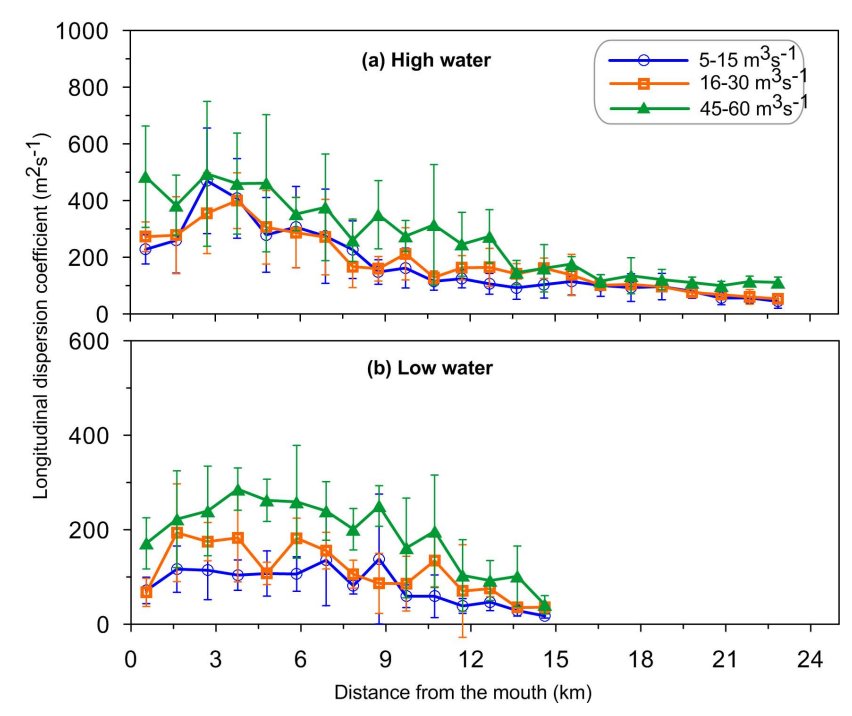

Fig. 4. Mean longitudinal dispersion coefficient $D_{i}\left(\mathrm{~m}^{2} \mathrm{~s}^{-1}\right)$ as a function of position along the Sumjin River Estuary for high water slack and low water slack conditions.

for a group of six estuaries. This range is consistent with that found at HWS in this study. However, de Swart et al. (1997) and Austin (2004) found a more wide range of dispersion coefficient. This inconsistency may be due to the variation in geometry and bathymetry of the estuaries. Banas et al. (2004) also found a decreasing trend in $D_{i}(x)$ from $710 \mathrm{~m}^{2} \mathrm{~s}^{-1}$ near the mouth to $20 \mathrm{~m}^{2} \mathrm{~s}^{-1}$ upstream, in agreement with this study. Vallino and Hopkinson (1998) found a dispersion coefficient of $670 \mathrm{~m}^{2} \mathrm{~s}^{-1}$ near the mouth of Parker River estuary. These values correspond with the maximum dispersion coefficient during high tide of this study.

In contrast, the range of longitudinal dispersion coefficient values is considerably smaller for LWS. These values range between 35 and $194 \mathrm{~m}^{2} \mathrm{~s}^{-1}$, with a mean value of $110 \mathrm{~m}^{2} \mathrm{~s}^{-1}$ for river discharge of $16-30 \mathrm{~m}^{3} \mathrm{~s}^{-1}$ at low tide
(Fig. 4b). The mean value of $D_{i}(x)$ is around $79 \mathrm{~m}^{2} \mathrm{~s}^{-1}$ with a range of $18-138 \mathrm{~m}^{2} \mathrm{~s}^{-1}$ for river discharge of $5-15 \mathrm{~m}^{3} \mathrm{~s}^{-1}$ and $184 \mathrm{~m}^{2} \mathrm{~s}^{-1}$ with a range of $41-286 \mathrm{~m}^{2} \mathrm{~s}^{-1}$ for river discharge of 45-60 $\mathrm{m}^{3} \mathrm{~s}^{-1}$ (Table 2). West and Williams (1972) found a range of $D_{i}(x)$ values between 50 and $300 \mathrm{~m}^{2} \mathrm{~s}^{-1}$ in Ems estuary, in agreement with this result. This also seems consistent with the result of Van de Kreeke (1990) who found a value between 150 and $325 \mathrm{~m}^{2} \mathrm{~s}^{-1}$ in Volkerak estuary. Monismith (2010) gives a range of values for $D(x)$, with typical dispersion values of $100-300 \mathrm{~m}^{2} \mathrm{~s}^{-1}$ for many estuaries. Lewis and Uncles (2003) suggested a representative longitudinal dispersion value of $100 \mathrm{~m}^{2} \mathrm{~s}^{-1}$ as a reasonable first choice for establishing a cross-sectionally averaged estuary model. Fischer et al. (1979) reported a typical dispersion value of $200 \mathrm{~m}^{2} \mathrm{~s}^{-1}$ for estuaries, particularly for tidal dispersion. These average values of this study are consistent with those suggested by Fischer et al. (1979), Lewis and Uncles (2003), and Monismith (2010).

The analysis of this study does not address the specific mechanisms responsible for this dispersion owing to a lack of velocity measurements. However, this quantitative knowledge of the spatially varying dispersive characteristics of the SRE can be useful for developing and testing hypotheses about various mixing mechanisms. This is the only example known to the authors of either temporal or spatial variability in dispersion estimates at high and low tide for the SRE. These data provide an important starting point for additional characterization of mixing processes in the SRE.

\subsection{Effects of river discharge and potential energy anomaly on longitudinal dispersion}

The longitudinal dispersion coefficient increases with increasing river discharge (Paulson, 1970; Garvine et al., 1992; Monismith et al., 2002; Austin, 2004). In this study, the temporally varying longitudinal dispersion appears to be positively correlated with river discharge at high and low tide (Figs. 5 and 6), respectively. Theoretically the dispersion is 


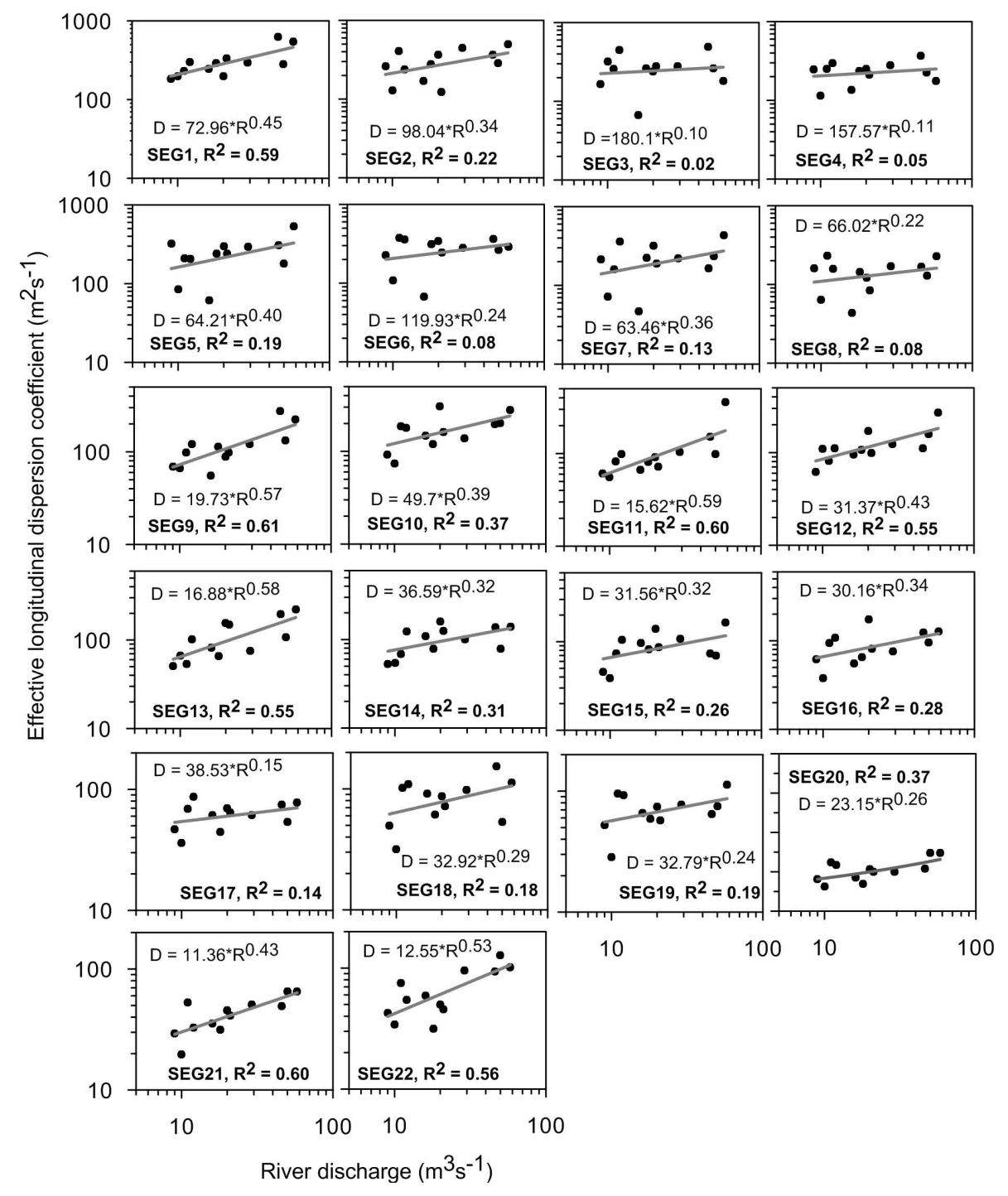

Fig. 5. Effective longitudinal dispersion coefficient $(D)$ estimated at high water slack versus river discharge $(R)$ at various positions along the Sumjin River Estuary.

a function of the square root of the river discharge (Eqs. 1.2 and 5.70; Savenije, 2005). The dispersion varies approximately with the root of the freshwater discharge in segments 1, 9, 11, 12, 13, 21 and 22 at HWS (Fig. 5). Some locations do not show this functional relationship between river discharge and longitudinal dispersion coefficient at high tide. This is because mixing in estuaries is determined in part by the bathymetry, and no combination of purely external inputs completely describes the process (Fischer, 1976). Moreover, Chatwin and Allen (1985) reported that the transport of salt at a given point in space may conveniently be considered to result from turbulent mean advection processes and turbulent diffusion processes. At LWS, the dispersion varies with the root of the freshwater discharge mostly in all segments except in 4, 9, 11, 12 and 13 (Fig. 6). As the tidal effect is minimal at LWS compared to that at HWS, and river discharge induces seaward advection at LWS, a more functional relationship between river discharge and longitudinal dispersion coefficient might be found at LWS than at HWS. Ward and Fischer (1971) noted that although $D(x, t)$ is a function of discharge at any given location for a range of dispersion values, the variability in $D(x, t)$ at $x$ could be due to the extreme complexity of estuarine systems including great variation in geometry and bathymetry as well as inappropriate application of the steady-state assumption for some salinity distributions because freshwater discharge varies over several orders of magnitude during the course of a year.

In addition, the temporally varying horizontal dispersion coefficient appears to be inversely proportional to the tidal heights, but there was no significant correlation (not shown). 


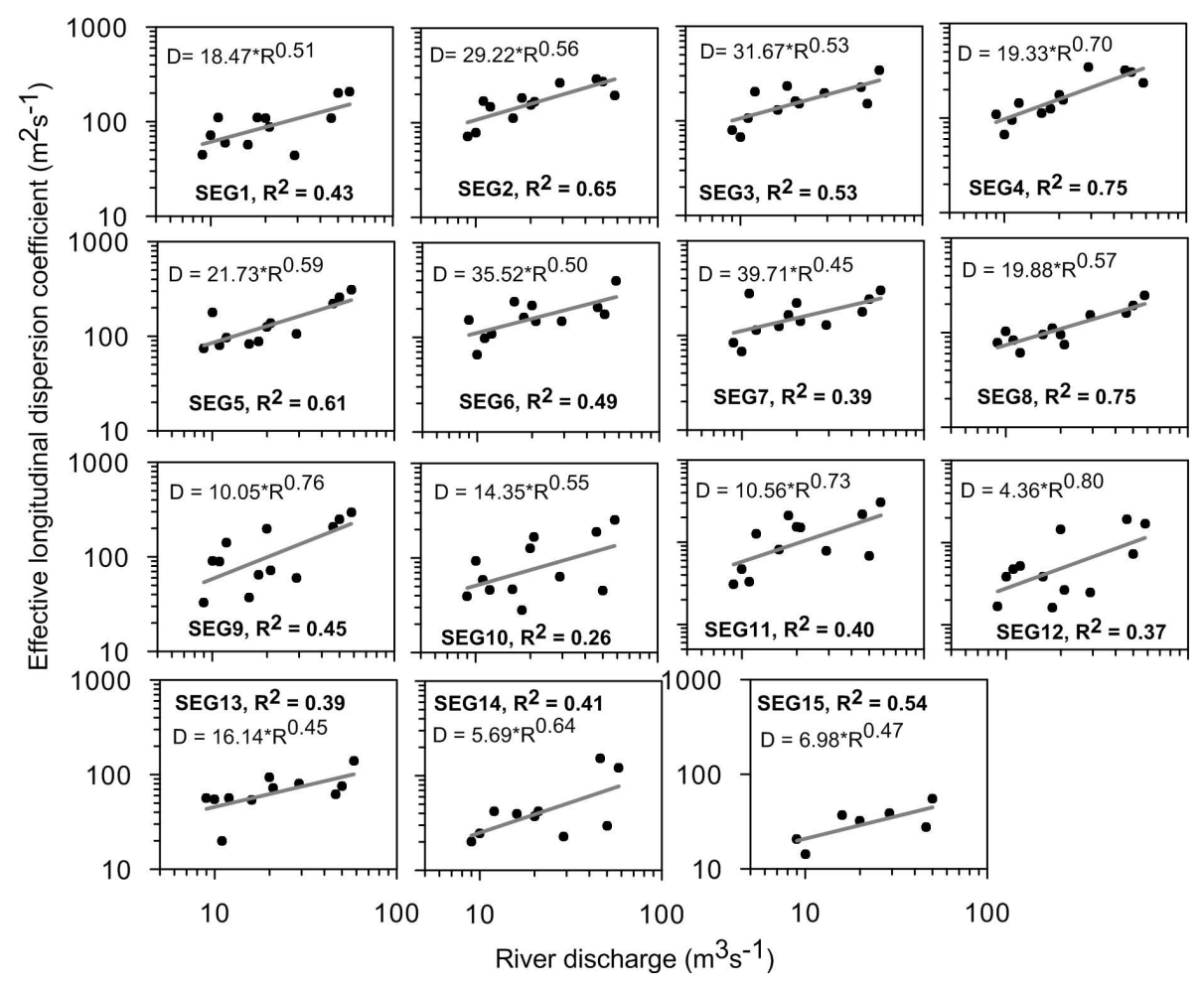

Fig. 6. Effective longitudinal dispersion coefficient $(D)$ estimated at low water slack versus river discharge $(R)$ at various positions along the Sumjin River Estuary.

Table 2. Longitudinal dispersion coefficients of the SRE for different river discharges.

\begin{tabular}{ccccc}
\hline Tide & $\begin{array}{c}\text { River discharge } \\
\left(\mathrm{m}^{3} \mathrm{~s}^{-1}\right)\end{array}$ & $\begin{array}{c}\text { Minimum } \\
\left(\mathrm{m}^{2} \mathrm{~s}^{-1}, \text { upstream }\right)\end{array}$ & $\begin{array}{c}\text { Average } \\
\left(\mathrm{m}^{2} \mathrm{~s}^{-1}\right)\end{array}$ & $\begin{array}{c}\text { Maximum } \\
\left(\mathrm{m}^{2} \mathrm{~s}^{-1}, \text { near mouth }\right)\end{array}$ \\
\hline \multirow{2}{*}{ HWS } & $5-15$ & 44 & 171 & 470 \\
& $16-30$ & 53 & 181 & 400 \\
& $45-60$ & 100 & 261 & 494 \\
\hline \multirow{3}{*}{ LWS } & $5-15$ & 18 & 79 & 138 \\
& $16-30$ & 35 & 110 & 194 \\
& $45-60$ & 41 & 184 & 286 \\
\hline
\end{tabular}

The tidal height data were collected from the Gwangyang tidal gauge station near the SRE's mouth. These data were used to examine the effects of tidal heights on the longitudinal dispersion coefficient because of a lack of observed tidal height data along the SRE. This may be one cause of an insignificant correlation between tidal height and longitudinal dispersion coefficient. This is attributed to turbulence generated by strong tidal currents, which effectively reduce the dispersing action of velocity shears (Linden and Simpson, 1988). Without corresponding velocity data (the observations lack velocity measurements), it is impossible to judge the relative contribution of shear flow dispersion by tidal currents. However, the fact that the dispersion increases with river discharge is consistent with previous studies.
The spatial variation in the potential energy anomaly at low and high tides along the SRE is shown in Fig. 7. The potential energy anomaly $(\phi)$ is the amount of work necessary to completely mix the water column $\left(\mathrm{Jm}^{-3}\right)$ and can be calculated using $\phi=\frac{1}{H} \int_{-H}^{0} g z(\bar{\rho}-\rho) d z$, where $\rho$ is the vertical density profile over a water column of depth $H, z$ is the vertical coordinate and $g$ is the gravitational acceleration $\left(9.8 \mathrm{~m} \mathrm{~s}^{-2}\right)$. The potential energy anomaly increases with increasing river discharges. As a result, the longitudinal dispersion increases with increasing potential energy on the water column. The potential energy anomaly at HWS (Fig. 7a) is $>10 \mathrm{Jm}^{-3}$ over the tidal excursion length for river discharge of $45-60 \mathrm{~m}^{3} \mathrm{~s}^{-1}$ at which the longitudinal dispersion coefficient is maximal. The potential energy anomaly is $<10 \mathrm{Jm}^{-3}$ over the tidal excursion length (landward $6 \mathrm{~km}$ ) at LWS and HWS for river discharge of $5-15 \mathrm{~m}^{3} \mathrm{~s}^{-1}$ and $16-30 \mathrm{~m}^{3} \mathrm{~s}^{-1}$ where the longitudinal dispersion coefficient is lower. Burchard and Hofmeister (2008) examined the dynamics of the potential energy anomaly at a location, where the water column is fully destabilized during flood, with a range of $\phi$ between 0 and $9 \mathrm{Jm}^{-3}$. According to the stratification parameter, well-mixed conditions are found near the mouth of the SRE during spring tide (Shaha and Cho, 2009). Therefore, it can be assumed that the effective longitudinal dispersion values should be maximal over the tidal excursion length 


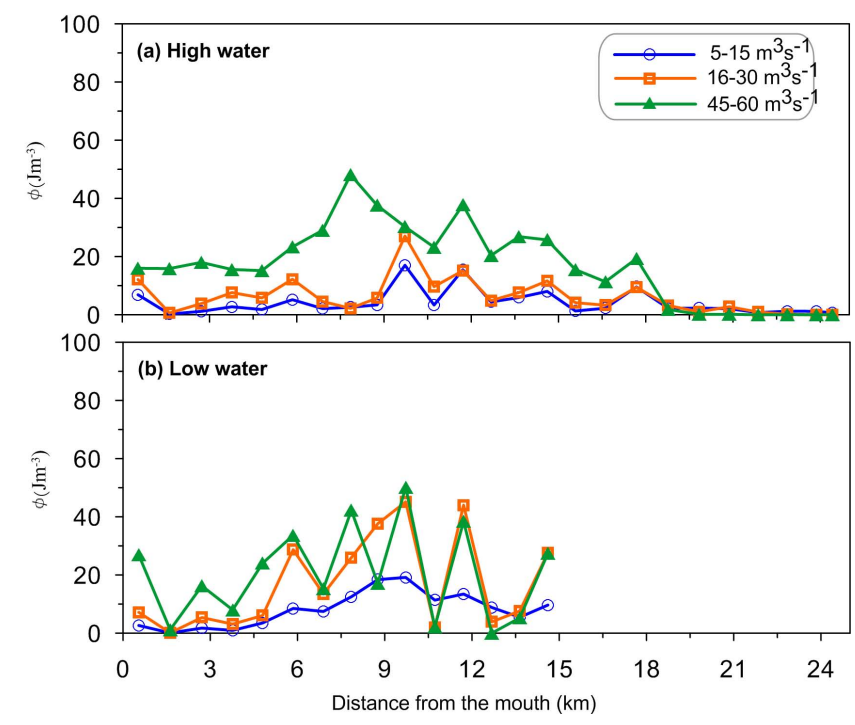

Fig. 7. Spatial variation in the potential energy anomaly at low and high tides along the Sumjin River Estuary under different river discharges.

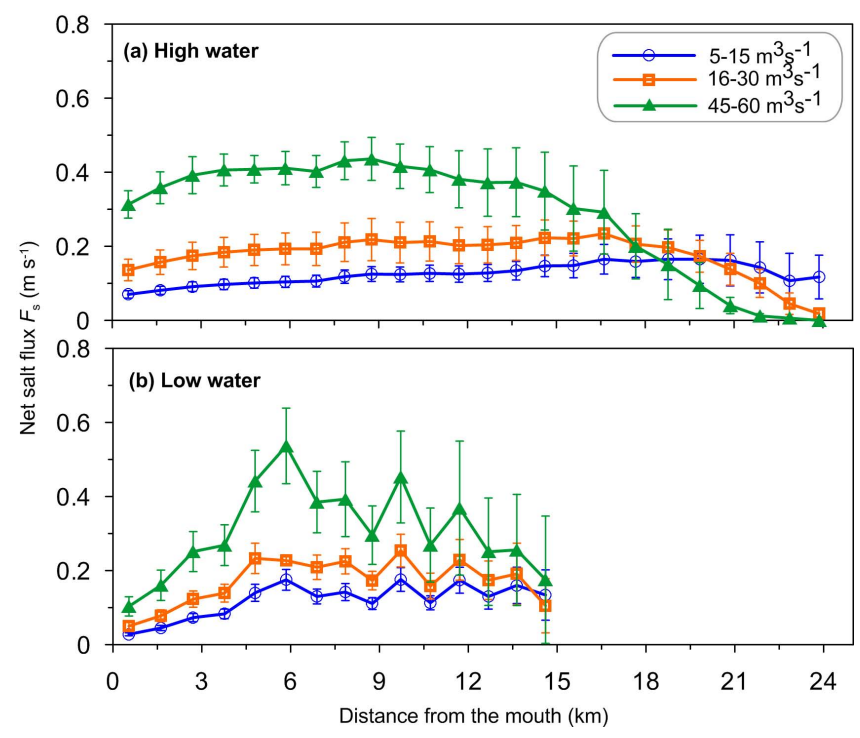

Fig. 8. Response of dispersive salt flux $F_{\mathrm{S}}\left(\mathrm{m} \mathrm{s}^{-1}\right)$ to salinity gradient $\left(\mathrm{km}^{-1}\right)$ at low and high waters along the Sumjin River Estuary under different river discharges.

scale observed in the SRE (Shaha and Cho, 2009). Banas et al. (2004) also found the maximum $D(x)$ value near the mouth. In contrast, $\phi$ increased to more than $11 \mathrm{Jm}^{-3}$ landward from the tidal excursion length of $6 \mathrm{~km}$, and the value of $D(x)$ decreased upstream.

\subsection{Link between salt fluxes and salinity gradient}

The spatially varying horizontal dispersion coefficient is inversely related to the salinity gradient; whereas the salt fluxes are proportional to the salinity gradient (Fig. 8). The low salt fluxes are associated with low salinity gradients and a low potential energy anomaly, whereas high salt fluxes are associated with high salinity gradients and a high potential energy anomaly. The net salt fluxes increases with increasing river discharges and decreases with decreasing river discharges at HWS and LWS (Fig. 8a-b).

As the cross-sectional area increases exponentially at the seaward end of the SRE (Shaha and Cho, 2011), the displacement of the salinity distribution for a particular isohaline decreases at the seaward end of the SRE. Therefore, the seaward advective transport of salt per unit area decreases to the mouth of the SRE from the upstream end at LWS because of maintaining mass balance. This result is consistent with that of Lewis and Uncles (2003). They reported that the rate of salt transport per unit area at the seaward end of a coastal plain estuary may be quite small because of the relatively large cross-sectional area, which leads to low residual currents.

On the other hand, the salt fluxes increase in the central regimes owing to the increasing salinity gradient. The seaward shifts of the salinity distribution in the central and inner regimes are much more sensitive at LWS than at HWS during high river discharge period because of mass balance between the regions of greater cross-sectional area (near the mouth) and shorter cross-sectional area (upstream). As a result the standard deviation of net salt fluxes is higher in the central regimes at LWS than at HWS.

\section{Conclusions}

Three years of hydrographic data taken along the main axis of the SRE are used to analyze the effective longitudinal dispersion coefficient. Using an advection-diffusion equation, the effective longitudinal dispersion is inferred as a function of space. The effective longitudinal dispersion is particularly sensitive near the mouth of the SRE at both HWS and LWS owing to the small salinity gradient. The maximum value of the temporally varying dispersion coefficient is $494 \mathrm{~m}^{2} \mathrm{~s}^{-1}$ near the mouth and decreases gradually upstream to $44 \mathrm{~m}^{2} \mathrm{~s}^{-1}$ at HWS. On the other hand, the mean dispersion value is approximately $110 \mathrm{~m}^{2} \mathrm{~s}^{-1}$ with a range between 18 and $194 \mathrm{~m}^{2} \mathrm{~s}^{-1}$ at LWS. The seaward advective transport of salt per unit area near the mouth of the SRE is decreased because of the relatively large cross-sectional area at the seaward end, which generates a small salinity gradient. This effective longitudinal dispersion appears to be positively correlated with river discharge at both HWS and LWS. The dispersion varies approximately with the square root of the 
river discharges at both HWS and LWS in many locations along the SRE which are consistent with the theory.

The salinity gradient decreases at the seaward end of the SRE and increases upstream by maintaining mass balance between greater cross-section area near the mouth and upstream locations. The dispersive flux of salt is particularly sensitive near the maximum salinity gradient in the central regimes at LWS because of the increasing displacement of isohalines. The salt flux increases with the salinity gradient and potential energy anomaly at both LWS and HWS.

These basic estimates of effective longitudinal dispersion and information about their spatial and temporal variability will provide an essential test for numerical models of this estuarine circulation. A better understanding of the principal hydraulic parameters controlling mixing such as the dispersion coefficient is therefore the prime requirement for an effective numerical simulation of estuarine circulation. Longitudinal velocity measurements using ADCP and experiment of 3-D numerical model will be performed to verify and refine the dispersion coefficients determined from salinity distribution in the next study.

Acknowledgements. This research was supported by the NAP program of the Korea Ocean Research Development Institute and the project titled on "Long-term change of structure and function in marine ecosystems of Korea" funded by the Ministry of Land, Transport and Maritime Affairs, Korea. The authors thank the members of the Marine Environment Prediction Laboratory for their enthusiastic supports during data collection.

Edited by: H. H. G. Savenije

\section{References}

Austin, J. A.: Estimation of effective longitudinal dispersion in the Chesapeake Bay, Estuar. Coast. Shelf S., 60, 359-368, 2004.

Bae, D. H., Jung, I. W., and Chang, H.: Long-term trend of precipitation and runoff in Korean river basins, Hydrol. Process., 22, 2644-2656, 2008.

Banas, N. S., Hickey, B. M., MacCready, P., and Newton, J. A.: Dynamics of Willapa Bay, Washington, a highly unsteady partially mixed estuary, J. Phys. Ocean., 34, 2413-2427, 2004.

Burchard, H. and Hofmeister, R.: A dynamic equation for the potential energy anomaly for analysing mixing and stratification in estuaries and coastal seas, Estuar. Coast. Shelf S., 77, 679-687, 2008.

Caplow, T., Schlosser, P., Ho, D. T., and Santella, N.: Transport dynamics in a sheltered estuary and connecting tidal straits: $\mathrm{SF}_{6}$ tracer study in New York Harbor, Environ. Sci. Technol., 37, 5116-5126, 2003.

Chatwin, P. C. and Allen, C. M.: Mathematical models of dispersion in rivers and estuaries, Ann. Rev. Fluid. Mech., 17, 119-149, 1985.

de Swart, H. E., De Jonge, V. N., and Vosbeek, M.: Application of the tidal random walk model to calculate water dispersion coefficients in the Ems estuary, Estuar. Coast. Shelf S., 45, 123-133, 1997.
Dyer, K. R.: Estuaries, A Physical Introduction, 2nd Edn., John Wiley, London, 195 pp., 1997.

Eaton, T. T.: Analytical estimates of hydraulic parameters for an urbanized estuary - Flushing Bay, J. Hydrol., 347, 188-196, 2007.

Fischer, H. B.: Mixing and dispersion in estuaries, Ann. Rev. Fluid Mech., 8, 107-133, 1976.

Fischer, H. B., List, E. J., Koh, R. C. Y., Imberger, J., and Brooks, N. H.: Mixing in Inland and Coastal Waters, 1st Edn, Academic Press, New York, 483 pp., 1979.

Garcia-Barcina, J. M., Gonzalez-Oreja, J. A., and De la Sota, A.: Assessing the improvement of the Bilbao estuary water quality in response to pollution abatement measures, Water Res. 40, 951960, 2006.

Garvine, R., McCarthy, R., and Wong, K.-C.: The axial salinity distribution in the Delaware estuary and its weak response to river discharge, Estuar. Coast. Shelf S., 35, 157-165, 1992.

Gay, P. and O'Donnell, J.: Comparison of the salinity structure of the Chesapeake bay, the Delaware bay and long Island sound using a linearly tapered advection-dispersion model, Estuar. Coast., 32, 68-87, doi:10.1007/s12237-008-9101-4, 2009.

Geyer, W. and Signell, R.: A reassessment of the role of tidal dispersion in estuaries and bays, Estuar. Coast., 15, 97-108, 1992.

Guymer, I. and West, J. R.: The determination of estuarine diffusion coefficients using a fluorimetric dye tracing technique, J. Hydraul. Eng., 118, 718-734, 1992.

Ho, D. T., Schlosser, P., and Caplow, T.: Determination of longitudinal dispersion coefficient and net advection in the tidal Hudson River with a large-scale, high resolution $\mathrm{SF}_{6}$ tracer release experiment, Environ. Sci. Technol., 36, 3234-3241, 2002.

Ji, Z. G.: Hydrodynamics and Water Quality: Modeling Rivers, Lakes and Estuaries, 1st Edn., John Wiley, New Jersey, USA, 676 pp., 2008.

Lewis, R. E. and Uncles, R. J.: Factors affecting longitudinal dispersion in estuaries of different scale, Ocean Dynam., 53, 197-207, 2003.

Linden, P. F. and Simpson, J. E.: Modulated mixing and frontogenesis in shallow seas and estuaries, Cont. Shelf Res., 8, 1107-1127, 1988.

MacCready, P.: Estuarine adjustment to changes in river flow and tidal mixing, J. Phys. Oceanogr., 29, 708-726, 1999.

MacCready, P. and Geyer, W. R.: Advances in estuarine physics, Annu. Rev. Mar. Sci., 2, 35-58, 2010.

Monismith, S. G.: Mixing in estuaries, in: Contemporary Issues in Estuarine Physics, edited by: Valle-Levinson, A, Cambridge University Press, Cambridge, 145-185, 2010.

Monismith, S. G., Kimmerer, W., Stacey, M. T., and Burau, J. R.: Structure and flow-induced variability of the subtidal salinity field in Northern San Francisco Bay, J. Phys. Ocean., 32, 30033019, 2002.

Officer, C. B.: Physical Oceanography of Estuaries (and Associated Coastal Waters), John Wiley, New York, USA, 465 pp., 1976.

Paulson, R. W.: Variation of the longitudinal dispersion coefficient in the Delaware River Estuary as a function of freshwater inflow, Water Resour. Res., 6, 516-526, 1970.

Prandle, D.: Salinity intrusion in estuaries, J. Phys. Oceanogr., 11, 1311-1324, 1981.

Savenije, H. H. G.: A one-dimensional model for salinity intrusion in alluvial estuaries, J. Hydrol., 85, 87-109, 1986.

Savenije, H. H. G.: Salt intrusion model for high water slack, low 
water slack and mean tide on spreadsheet, J. Hydrol., 107, 9-18, 1989.

Savenije, H. H. G.: Salinity and Tides in Alluvial Estuaries, 1st Edn., Elsevier, Amsterdam, 197 pp., 2005.

Shaha, D. C. and Cho, Y.-K.: Comparison of empirical models with intensively observed data for prediction of salt intrusion in the Sumjin River estuary, Korea, Hydrol. Earth Syst. Sci., 13, 923933, doi:10.5194/hess-13-923-2009, 2009.

Shaha, D. C. and Cho, Y.-K.: Determination of spatially varying Van der Burgh's coefficient from estuarine parameter to describe salt transport in an estuary, Hydrol. Earth Syst. Sci., 15, 13691377, doi:10.5194/hess-15-1369-2011, 2011.

Shaha, D. C., Cho, Y.-K., Seo, G.-H., Kim, C.-S., and Jung, K. T.: Using flushing rate to investigate spring-neap and spatial variations of gravitational circulation and tidal exchanges in an estuary, Hydrol. Earth Syst. Sci., 14, 1465-1476, doi:10.5194/hess14-1465-2010, 2010.
Vallino, J. J. and Hopkinson, Jr. C. S.: Estimation of dispersion and characteristic mixing times in Plum Island Sound Estuary, Estuar. Coast. Shelf S., 46, 333-350, 1998.

Van de Kreeke, J.: Longitudinal dispersion in the Volkerak Estuary, in: Cheng RT, Residual currents and long-term transport, Lecture notes on coastal and estuarine studies, Springer, Berlin Heidelberg New York, 38, 151-164, 1990.

Ward, P. R. B. and Fischer, H. B.: Some limitations on use of the one-dimensional dispersion equation, with comments on two papers by: R. W. Paulson, Water Resour. Res., 7, 215-220, 1971.

West, J. R. and Williams, J. R. A.: An evaluation of mixing in the Tay estuary, ASCE, Proceedings of the 13th conference on civil engineering Washington, DC, 2153-2169, 1972. 